\title{
Observations on a new family showing bisalbuminaemia of the slow type
}

\author{
TERESA MIKULSKA ${ }^{1}$, PAWE⿺ MIKULSKI², AND JERZY ROGULSKI \\ From the Department of Clinical Biochemistry, Medical Academy, Gdañsk-6, Poland
}

SYNOPSIS A new family with an electrophoretically more slowly moving albumin variant is des-w cribed. The pattern of variance was studied using three different electrophoretic techniques, ancक्त. compared with certain other known fast and slow variants. Features of penicillin and brom phenol blue binding by normal and variant albumins were also studied. Both normal human albumin and the albumin variant treated with penicillin broadened and moved faster. Native albumin $A, \vec{\circ}$ prestained with bromphenol blue, binds approximately twice as much of the dye as the slow-moving variant. On the other hand, staining of denatured proteins on paper showed that both bands takeo up equal amounts of dye.

During the past 10 years there have been several reports of albumin variants detected in routine paper or cellulose acetate electrophoresis. Several more negatively and more positively charged albumins in different populations have also been found (Weitkamp, Franglen, Rokala, Polesky, Simpson, Sunderman, Bell, Saave, Lisker, and Bohls, 1969). In most of the reported cases the albumin variant has been shown to be inherited as a simple autosomal codominant trait, and the presence of two albumin bands led to the use of the term 'bisalbuminaemia' for this condition. Bisalbuminaemia was found to be extremely rare in the populations in which it was found (Melartin, 1967). The heterozygotes did not have any clear evidence of disease. The trait is thought to be permanent but there have been reports of transient bisalbuminaemia (Scheurlen, 1955; Gabl and Huber, 1964). Moreover, the occurrence of transient acquired bisalbuminaemia in patients receiving large amounts of penicillin has been described (Arvan, Blumberg, and Melartin, 1968). Recently it has been shown that the slow albumin variant takes up less bromphenol blue than the normal band and the fast variant takes up more dye (Tárnoky, Dowding, and Lakin, 1970).

In this communication we report another family with an electrophoretically more slowly moving albumin variant. Features of penicillin and brom-

\footnotetext{
${ }^{1}$ Present address: Laboratory of Toxicology, Industrial Medical Centre, Elblag.

'Present address . Institute of Marine Medicine, Gdańsk.

Received for publication 25 July 1972.
}

phenol blue binding by normal and variant albumins ${ }^{\mathbb{D}}$ are also reported.

\section{Materials and Methods}

The subject was a healthy female laboratory technician. Bisalbuminaemia was found on a routine paper electrophoresis. Blood was drawn by vene-응 puncture from the subject and other members of the family. After clotting the serum was separated andō kept frozen. Serum paper electrophoresis was performed using Whatmann no. 1 filter paper and barbiturate buffer at $p \mathrm{H} 8.6$ and ionicity of 0.10 Electrophoresis was allowed to proceed for 18 hourss at 4 volts per $\mathrm{cm}$. Satisfactory separation of the albumin fraction was, however, obtained if shorter. runs (six hours) were carried out. Staining was by bromphenol blue, azocarmin B, or amido black (Smith, 1968). Agar-gel electrophoresis was performed exactly according to the method of Wieme (1959), and cellulose acetate electrophoresis using a Sar=o torius membrane filter. Runs were performed for one hr at $200 \mathrm{v}$ in $0.036 \mathrm{M}$ barbiturate buffer $p \mathrm{H} \mathrm{8.6} \mathrm{N}$ staining was done by amido black. Total serum protein was measured by the biuret reaction, and relative protein fractions were determined after
elution from the paper (Henry, 1966).

The effect of penicillin on the mobility of albumine variants was measured in vitro as follows: potassium penicillin G (Polfa, Poland) was reconstituted in $0 \cdot 1 \mathrm{M}$ phosphate buffer $p \mathrm{H} \mathrm{7 \cdot 4}$. Different dilutions of antibiotic were added to an equal volume of serump 
so that the final concentration of penicillin ranged from 100 to 50000 units per $\mathrm{ml}$. The mixtures were incubated in a $37^{\circ} \mathrm{C}$ water bath for three hours and then subjected to agar-gel electrophoresis.

Measurements of the relative bromphenol blue binding abilities of two albumins were carried out by adding different concentrations of bromphenol blue made in barbiturate buffer $(0.1 \mathrm{M}, \mathrm{pH} 8.6)$ to an equal volume of serum so that the final concentration of dye ranged from 0.0025 to $1.0 \%$. The mixtures were incubated in $37^{\circ}$ water bath for one hour and then subjected to filter paper electrophoresis. Prestained with bromphenol blue electrophoretograms were dried and dissected along the longitudinal axis. The albumin areas were cut from one half of the strip, eluted, and quantitated at $590 \mu \mathrm{m}$. The second half of the strip was stained again with azocarmin $B$, the albumin areas were then cut from the paper, eluted, and quantitated at $520 \mu \mathrm{m}$. The $\mathrm{E}_{590} / \mathrm{E}_{520} \times 100$ ratio was used as an index of bromphenol blue-binding abilities of two albumin variants in their native state. The possibility of a large analytical error in this procedure was appreciated. The coefficient of variation of the $E_{590} / E_{520}$ ratio, calculated for a large series of strips treated in the same manner, was found not to exceed $7 \%$. Essentially similar results were obtained when two carefully measured samples of the same albumin solution incubated with bromphenol blue were subjected to electrophoresis on separate strips and one of them was restained with azocarmin B.

\section{Results}

The paper electrophoretogram of the serum of the subject is shown in Figure 1A. It can be seen that there is a definite splitting of the albumin fraction and that the paraalbumin fraction is completely separated from the alpha-1 globulin and the normal albumin as well. No other electrophoretic abnormalities are apparent. Agar-gel electrophoresis as well as electrophoresis on cellulose acetate clearly resolved the variant protein from the main albumin band (Figs. 1B and C). The electrophoretic patterns of sera from members of the proposita's family are presented in Figure 2. It can be seen that the mother of the family and the female sibling have the anomaly. The anomalous albumin appeared as a slower one migrating in the region of albumin $B$. The variant protein evaluated after dye elution from filter paper represents about $50 \%$ of the total albumin. The relative concentrations of all the protein fractions in all members of the family are given in Table $I$. The total concentration of albumin is normal, and the amounts of slow-moving albumin are approximately equal to the amounts of normal serum albumin (albumin A). The subjects presenting the anomalous trait were normal in all other respects. of proposita's serum. (A) filter paper electrophoresis, (B) cellulose acetate electrophoresis, (C) agar-gel electrophoresis. 


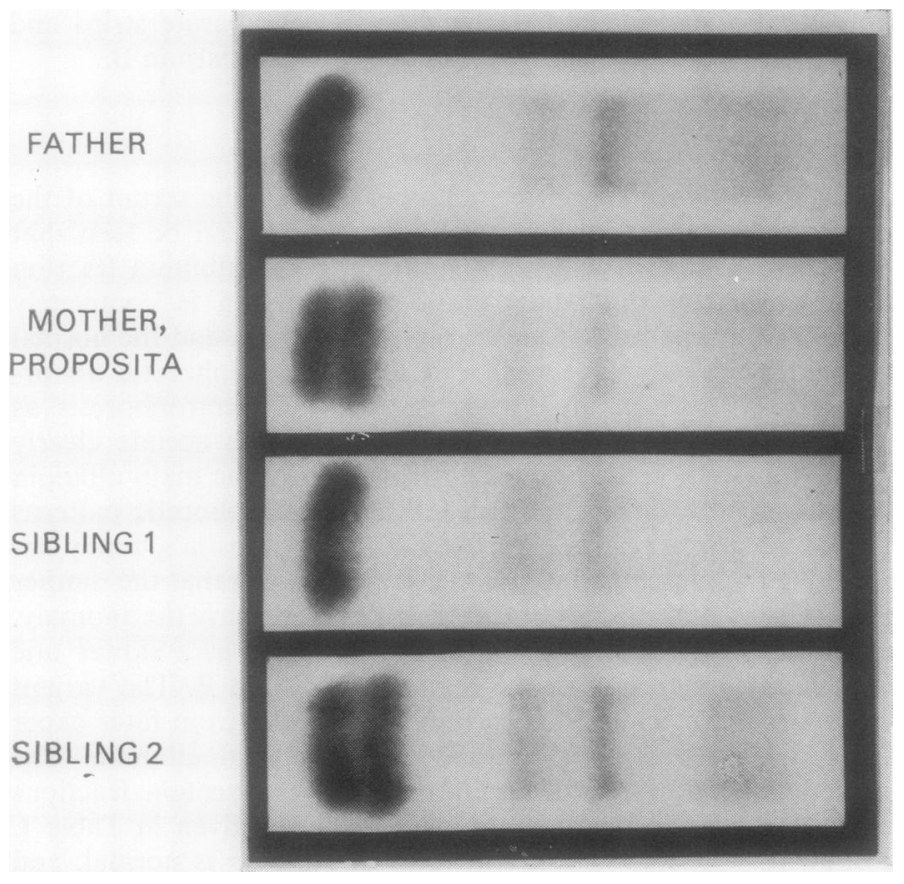

Fig. 2 Filter paper electrophoresis of sera from entire family.

It was found that two albumin bands could still be clearly separated by filter paper or agar-gel electrophoresis after the specimens had been kept frozen for several months. After storage at 0 to $4^{\circ}$ for six months the separation of two bands was less clear-cut but still evident.

The electrophoretic pattern of the anomalous albumin is shown in Figure 3. In this, the slowly migrating variant is compared to albumin A (a common albumin), albumin Mexico (a slow moving albumin), and albumin Algonkian (a fast-moving albumin). ${ }^{1}$ The variant albumin under study migrates much more slowly than does albumin Mexico, and

${ }^{1}$ We are indebted to Dr H. F. Polesky of Minneapolis War Memorial Blood Bank, Minneapolis, Minn, USA, for kindly supplying these serum samples. can be clearly distinguished from albumin Mexece on cellulose acetate and filter paper (Fig. 3) as as on starch-gel electrophoresis (personal communio cation by $\mathrm{Dr}$ H. F. Polesky).

The biochemical differences between albumir variants which result in differences in electrophoreti $\vec{E}$ mobility might also have an effect on their binding properties for particular substances. It has been shown that penicillin in large amounts distorts the appearance of all albumin variants with which it has been associated (Arvan et al, 1968). Figure 4A show? the electrophoretic patterns of normal serum before. and after incubation with a concentration of peniog cillin (25000 units per $\mathrm{ml})$. It appears that the albumin A band broadens and moves faster thar normal human albumin. The effect of penicillin orp

\begin{tabular}{|c|c|c|c|c|c|c|c|c|}
\hline Family Member & $\begin{array}{l}\text { Total } \\
\text { Protein }^{1} \\
(\mathrm{~g} / \mathrm{l}(00 \mathrm{ml})\end{array}$ & $\begin{array}{l}\text { Albumin } A \\
(\%)\end{array}$ & $\begin{array}{l}\text { Albumin } B \\
(\%)\end{array}$ & $\begin{array}{l}\text { Alpha-l } \\
\text { Globulin } \\
(\%)\end{array}$ & $\begin{array}{l}\text { Alpha-2 } \\
\text { Globulin } \\
(\%)\end{array}$ & $\begin{array}{l}\text { Beta } \\
\text { Globulin } \\
(\%)\end{array}$ & $\begin{array}{l}\text { Gamma } \\
\text { Globulin } \\
(\%)\end{array}$ & $\begin{array}{l}\text { Albumin } \\
\text { Ratio } \\
A / B\end{array}$ \\
\hline Father (age 37) & $7 \cdot 0$ & $61 \cdot 0$ & - & $2 \cdot 7$ & $8 \cdot 0$ & $10 \cdot 8$ & $17 \cdot 5$ & $\ldots$ \\
\hline Mother (age 31) (proposita) & $7 \cdot 0$ & $31 \cdot 4$ & $32 \cdot 5$ & $3 \cdot 2$ & $6 \cdot 4$ & $8 \cdot 7$ & $15 \cdot 1$ & $1 \cdot 18$ \\
\hline Sibling 1 (male age 10$)$ & $6 \cdot 4$ & $68 \cdot 6$ & - & $2 \cdot \overline{8}$ & $11 \cdot 4$ & $5 \cdot 8$ & $11 \cdot 4$ & $\ldots$ \\
\hline Sibling 2 (female age 7 ) & $6 \cdot 8$ & $29 \cdot 8$ & $27 \cdot 8$ & $3 \cdot 0$ & 10.7 & $18 \cdot 0$ & $10 \cdot 7$ & $1 \cdot 07$ \\
\hline Normal for this laboratory & $6 \cdot 8$ & $61 \cdot 4$ & - & $3 \cdot 9$ & $6 \cdot 4$ & $9 \cdot 5$ & $18 \cdot 8$ & - \\
\hline
\end{tabular}

Table I Serum protein analysis on members of a family with bisalbuminaemia by filter paper electrophoresis 


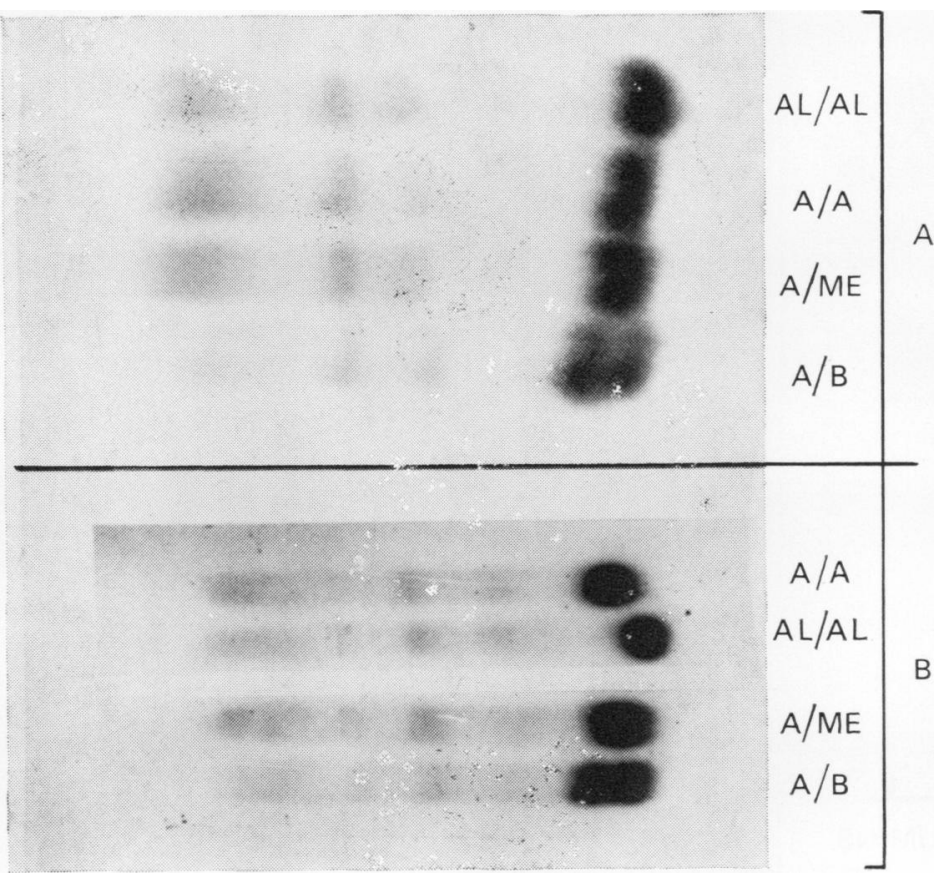

Fig. 3 Comparative electrophoresis of slow-moving albumin variant $(\mathrm{A} / \mathrm{B})$ with albumin $A(\mathrm{~A} / \mathrm{A})$, albumin Mexico (A/Me), and albumin Algonkian (AL/AL). (A) Filter paper electrophoresis; (B) cellulose acetate electrophoresis.

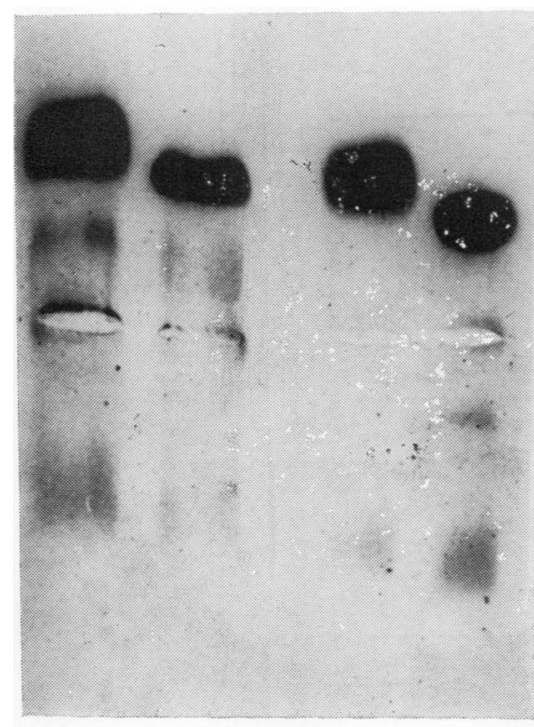

A

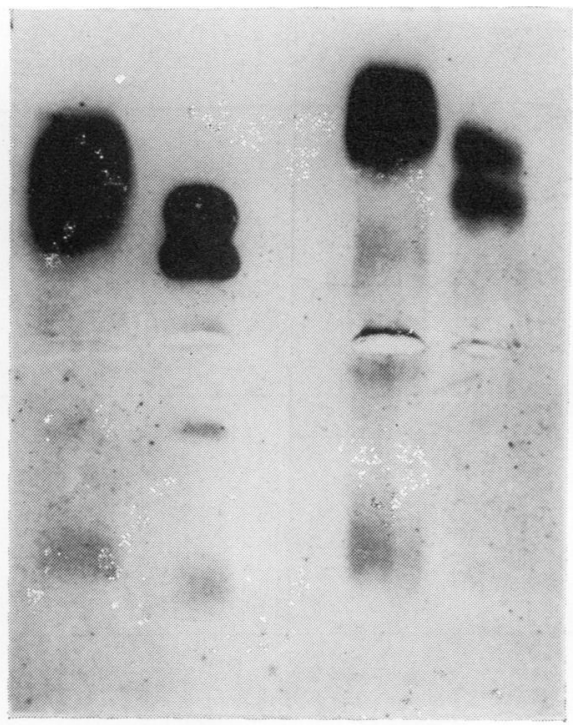

B

Fig. 4 Effect of penicillin (25000 units/ml) on the albumin of normal serum (A), and on the albumins of bisalbuminaemic serum (B). 


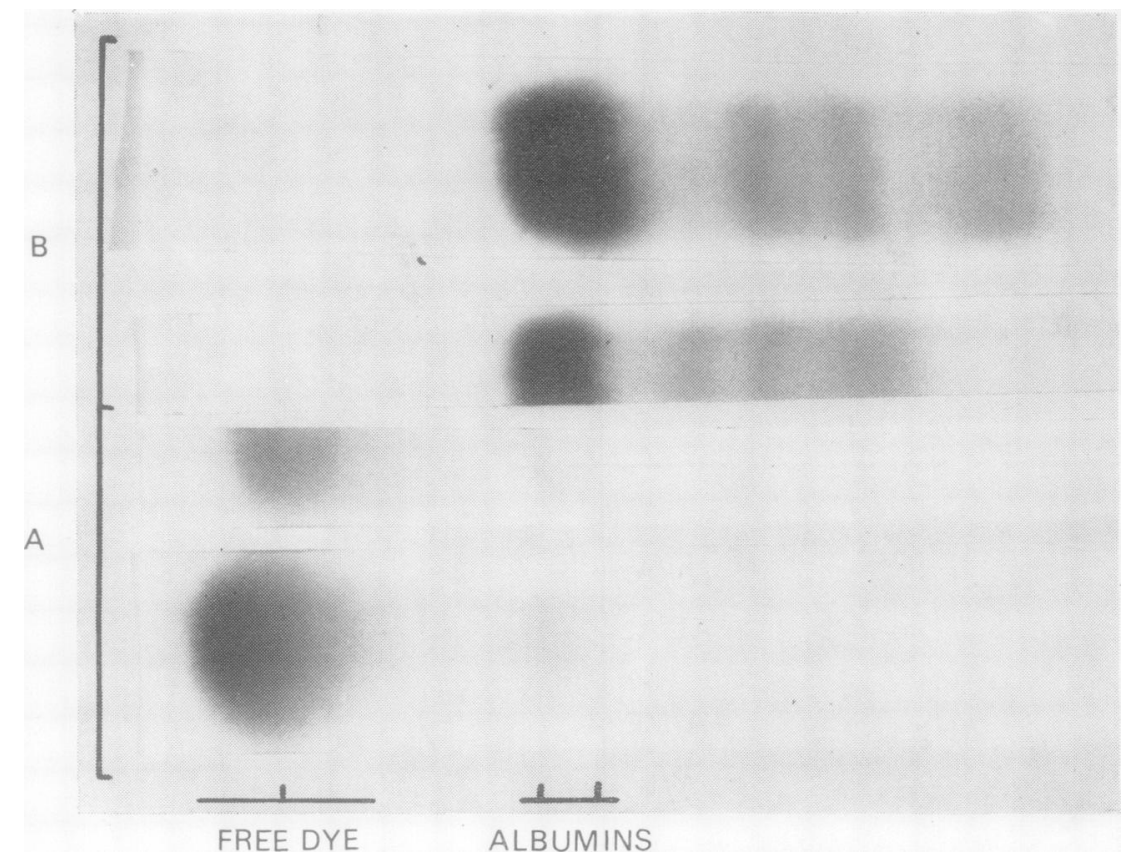

Fig. 5 Binding of bromphenol blue by albumin $A$ and albumin $B$ of bisalbuminaemic serum in native $(\mathrm{A})$ and in denatured state $(\mathrm{B})$.

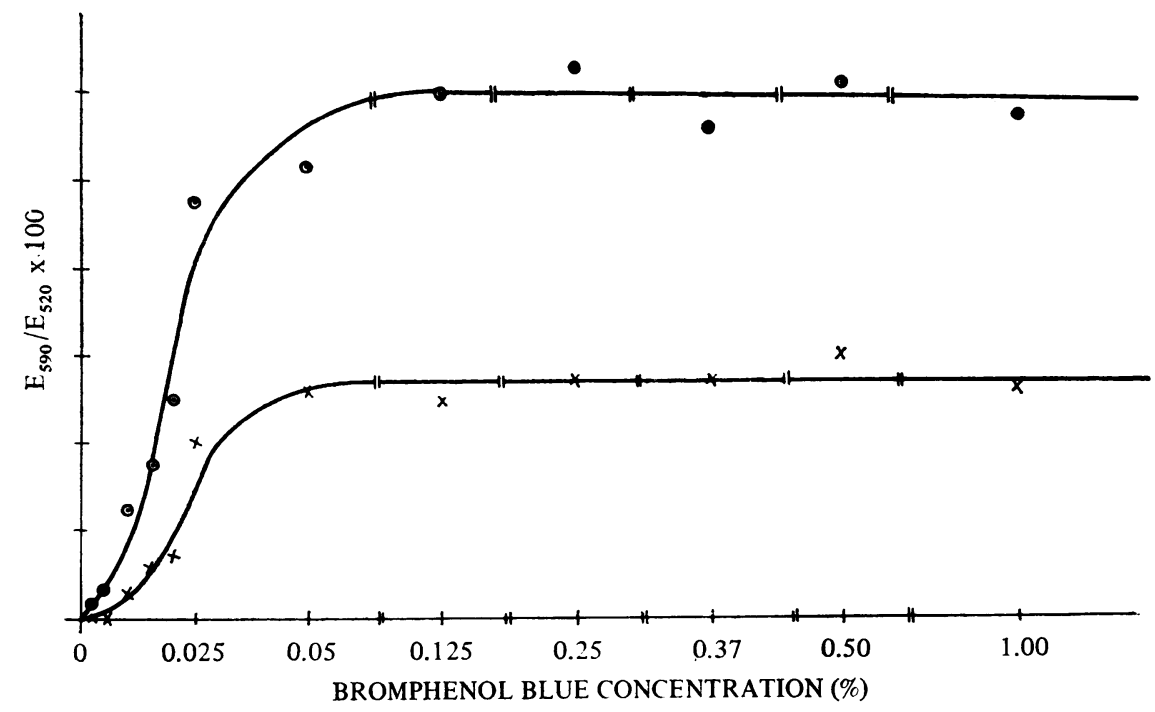

Fig. 6 Bromphenol blue binding abilities of two albumin variants in the native state. Uptake of dye versus its concentration for normal (upper curve) and slow-moving variant (lower curve). 
the albumins of the patient with bisalbuminaemia was studied under similar conditions (Fig. 4B). It is apparent that both variants move faster than they usually do. Both bands, however, broaden and fuse so that only one wide band can be visualized. The increase in mobility of both albumin variants is apparent at a concentration as low as 1000 units/ $\mathrm{ml}$. Pretreatment of penicillin with penicillinase abolished this effect.

Tárnoky et al (1970) have suggested that there is a qualitative difference in dye uptake between albumin variants prestained with bromphenol blue. We have attempted to evaluate this problem by measurement of dye bound by native, not denatured, albumins (Figs. 5 and 6). When a small amount of bromphenol blue was added to the bisalbuminaemic serum the dye travelled with the normal albumin only. Increasing the amount of dye led to the preferential marking of the electrophoretically normal albumin. It is apparent that the native albumin A binds approximately twice as much of bromphenol blue as the slow-moving variant (albumin B). It can be seen (Fig. 6) that at the final concentration of bromphenol blue as the slow-moving variant (albumin B). At the final concentration (Fig. 6) of bromphenol blue, ranging from 0.025 to $0.050 \%$, the binding abilities of both albumin variants became saturated. Even in the presence of a large excess of dye the native slow-moving variant takes up no more than about $50 \%$ of dye bound by normal albumin. On the other hand, staining of denatured protein on the paper revealed that both bands of albumin take up approximately equal amounts of dye (Fig. 5).

\section{Discussion}

Bisalbuminaemia is a rare inherited condition with no clinical features, in which the plasma contains two albumins of different electrophoretic mobilities, usually at equal concentration. In all the families so far described one of the albumins has migrated at the same rate as normal albumin. In some families the second albumin migrated more slowly and in others more rapidly. We are reporting the first bisalbuminaemic family found in Poland. The subject having an electrophoretically more slowly moving albumin variant was supposed to be of Jewish origin. Although genetic studies outside the immediate family were not possible, the results are consistent with the hypothesis that the variant (albumin B) is inherited as a simple autosomal codominant trait and the affected individuals are heterozygous for a gene controlling the formation of albumin proteins.
The electrophoretic pattern of the variant shows that the anomalous albumin moves much more slowly than the albumin Mexico. It may be compared to the types 1 and 5 or 6 of the largest comparative series of European families with inherited bisalbuminaemia reported by Tárnoky et al (1970). Our variant also resembles the one described by Franglen, Martin, Hargreaves, Smith, and Williams (1960) in that zone electrophoresis on paper, cellulose acetate, and agar all displayed a well defined double band having a mobility similar to that of albumin and faster than that of the alpha-1-globulin. All of these types migrate more slowly than normal human albumin as examined by three electrophoretic methods. However, the description of known electrophoretic variants of human serum albumin as electrophoretically 'slow', 'faster', and so on is becoming inadequate for classification. Tárnoky et al (1970) suggested the specificity of bromphenol blue binding as a test which would serve, among others, to characterize albumin variants. They reported that slow alloalbumins take up less dye than the normal band, and fast variants take up more. It seems that a comparison of amounts of dye bound to particular albumin variants in the native and denatured state might be useful to give more precise descriptions of variants. The difference in bromphenol blue-binding abilities between electrophoretically normal and slow-moving albumins is definite and might be measured quantitatively.

The trait is thought to be permanent but there have been reports of transient acquired 'bisalbuminaemia' in patients receiving intravenous infusions of penicillin (Arvan et al, 1968). This does not appear to have an inherited basis. Our experiments in vitro on albumin binding of penicillin showed that penicillin alters the electrophoretic mobilities of both variants. In agreement with the results of Arvan et al (1968), albumins treated with penicillin broaden and move faster. We have observed this effect at various concentrations of antibiotic. On the other hand, we have not been able to demonstrate definite splitting of albumin bands at any concentration of penicillin. It seems that the composition of the mixture and conditions of incubation with penicillin should be carefully studied in order to obtain more valuable suggestions on binding properties of albumin variants for penicillin. At present, there does not appear to be any differential binding of penicillin between albumin A and B variants. It seems worthwhile to mention here that Mackay and Martin (1956) showed that at $56^{\circ}$ human albumin would split into two components demonstrable by electrophoresis.

The results obtained suggest that the binding of penicillin may involve groups different from those 
in protein dye binding although other explanations are possible.

We wish to thank Dr S. Angielski for his interest during the course of this investigation.

\section{References}

Arvan, D. A., Blumberg, B. S., and Melartin, L. (1968). Transient 'bisalbuminemia' induced by drugs. Cilin. chim. Acta, 22, 211-218.

Franglen, G., Martin, N. H., Hargreaves, T., Smith, M. J. H., and Williams, D. I. (1960). Bisalbuminaemia: a hereditary albumin abnormality. Lancet, 1, 307-308.

Gabl, F., and Huber, E. G. (1964). Passagere, nicht hereditäre Doppelalbuminämie. Ann. paediat. (Basel), 202, 81-91.
Henry, R. J. (1966). Clinical Chemistry: Principles and Technics, pp. 182 and 216. Harper and Row, New York.

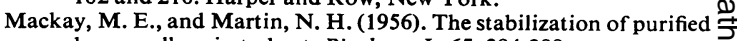
human albumin to heat. Biochem. J., 65, 284-288.

Melartin, L. (1967). Albumin polymorphism in man: studies on albumin variants in North American native populations. Acta path. microbiol. scand., Suppl., 191.

Scheurlen, P. G. (1955). Ueber Serumeiweissveränderungen beim7 Diabetes mellitus. Klin. Wschr., 33, 198-205.

Smith, I., Ed. (1968). Chromatographic and Electrophoretic Techniques, Vol. II, p. 26. Heinemann, London.

Táinoky, A. L., Dowding, B., and Lakin, A. L. (1970). Eight types of bisalbuminaemia. Nature (Lond.), 225, 742-743.

Weitkamp, L. R., Franglen, G., Rokala, D. A., Polesky, H. F., له Simpson, N. E., Sunderman, F. W., Jr., Bell, H. E., Saave, J., Lisker, R., and Bohls, S. W. (1969). An electrophoretic com- $\vec{\odot}$ parison of human serum albumin variants: eight distinguishable types. Hum. Heredity, 19, 159-169.

Wieme, R. J. (1959). An improved technique of agar-gel electro- $\vec{\omega}$ phoresis on microscope slides. Clin. chim. Acta, 4, 317-321. 